
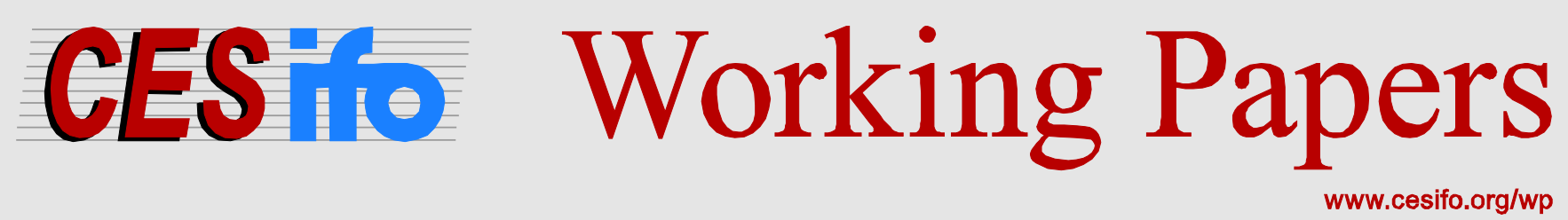

\title{
Singin' in the Rain: A Study of Social Pressure on the Soccer Field
}

\author{
Mikael Priks
}

\author{
CESIFO WORKING PAPER NO. 4481 \\ CATEGORY 13: BEHAVIOURAL ECONOMICS \\ NOVEMBER 2013
}
An electronic version of the paper may be downloaded
- from the SSRN website: WwW.SSRN.com
- from the RePEc website: Www.RePEc.org
- from the CESifo website: www.CESifo-group.org/wp

\section{CESifo}




\title{
Singin' in the Rain: A Study of Social Pressure on the Soccer Field
}

\begin{abstract}
Although social pressure may affect the behavior of individuals, it is very hard to evaluate empirically. A soccer field is an attractive testing ground in the sense that both performance and social pressure by spectators are measurable. The drawback is that the number of spectators is an endogenous variable. To solve this problem, I use pre-game precipitation as an instrument for the number of spectators at Swedish soccer games as it reduces attendance but not relative performance on the field. I find that organized home supporters manage to generate home wins. Highly skilled athletes are consequently influenced by social pressure, which can also help explain the well-known home field advantage.
\end{abstract}

JEL-Code: D800, J200, K400.

Keywords: social pressure, bias, home-field advantage.

\author{
Mikael Priks \\ Department of Economics \\ Stockholm University \\ Sweden - 10691 Stockholm \\ mikael.priks@ne.su.se
}

I thank Per Pettersson-Lidbom and Jakob Svensson for helpful comments. 


\section{Introduction}

Traditional economic theory does not take into account the possibility that individuals' choices are affected by social pressure. Following a theoretical contribution by Akerlof and Kranton (2000), a recent empirical economics literature has started to shed light on this question. Della Vigna et al. (2012) find that social pressure is an important determinant of door-to-door fund raising. Falk and Ichino (2006), who use an experiment and Mas and Moretti (2009), who use data on supermarket cashiers, show that peer pressure exists in the work place. Gerber et al. (2008) report that social pressure increases voter turnout. A distinctive feature of social pressure is that it is difficult to measure in most environments. Soccer games provide an exception in that social pressure approximated by the number of spectators attending a game as well as individuals' performance can be readily measured. A number of papers have consequently studied how soccer referees are affected by social pressure; see, e.g., Nevill and Holder (1999), Sutter and Kocher (2004), Garicano et al. (2005) and Dohmen (2008a). However, this literature has not taken into account the fact that the number of spectators is an endogenous variable, which may bias the results. ${ }^{3}$ Moreover, if spectators manage to influence the game through social pressure, then the effect is likely to arise foremost from organized supporters who are more visible and boisterous than other spectators, such as families and business people. So far, however, data on these types of supporters have not been available.

I address these problems by using unique police intelligence data on the number of organized supporters, game by game and team by team, in the highest Swedish soccer league, and by using precipitation, which obviously is exogenous to game outcome as an instrument for the number of organized home supporters. I found that precipitation during a pre-game day is a strong predictor of attendance. For example, $5 \mathrm{ml}$. of precipitation leads to approximately a 10-percent reduction in the number of organized home supporters. I then studied whether these supporters manage to influence the outcome of a game and found strong support for the social pressure hypothesis. A 10-percent reduction

\footnotetext{
${ }^{3}$ An exception is Pettersson-Lidbom and Priks (2010), who exploit the fact that some Italian soccer teams temporarily had to play games without spectators due to an exogenous hooligan incident. They show that referees are favorable towards home teams when influenced by social pressure.
} 
in the number of organized home supporters in the stadium leads to a 4-percent reduction in the probability of a home win.

It is, of course, important that the precipitation instrument does not affect the outcome of a game. It could be argued that precipitation makes the game outcome more unpredictable, thereby making draws more likely. I addressed this by controlling for precipitation during game day, and found that this does not affect the results qualitatively.

I also present suggestive evidence regarding the effect of the number of spectators on the home-field advantage. The result shows that the total number of spectators does not affect the probability of a home win, even though most of the spectators support the home team. In other words, I did not find support for a home-field advantage effect when measuring the number of spectators as in the previous literature.

Both players and referees may be affected by social pressure. In an attempt to disentangle the two effects, I show that referees do not favor the home team in terms of yellow and red cards in games with many organized home supporters. This indicates that it is the players rather than the referees who are sensitive to pressure from the crowd.

In a nutshell, I find that not only do charity givers, cashiers and voters respond to social pressure, as has been shown previously, but that there is also a large causal effect on the behavior of professional soccer players. The result also helps explain the strong home-field advantage in sports; see, e.g., Schwartz and Barsky (1977) for various team sports, Clarke and Norman (1995) for soccer, Morley and Thomas (2005) for cricket, Balmer et al. (2005) for boxing, and Koning (2005) for speed skating. Arguments such as travel fatigue (Nevill and Holder, 1999), familiarity with local conditions (Pollard, 2002) and hormones (Neave and Wolfson, 2003) have been used to explain this phenomenon. Here, I extend this analysis by showing that social pressure from organized home supporters may cause this phenomenon. In a related paper, Dohmen (2008b) finds that home players choke under pressure, i.e., shoot penalty kicks outside the goal, more than away players, when they face hostile faces behind the goal. This speaks against the homefield advantage hypothesis, but it supports the view that players are affected by social pressure from the crowd. While my analysis is the first to use weather as an instrument in the context of social pressure, it has previously been used as an instrument for income; see Paxson (1992), Miguel et al. (2004) and Miguel (2005). 
Vast costs are associated with policing soccer games and there is currently a heated debate in Europe regarding who should pay for these costs; see, e.g., BBC April 9, 2003 and The Guardian, August 28, 2009. Indications are that soccer clubs may tend to be reluctant to contribute to this cause by investing in guards, surveillance cameras and other equipment, etc. While they are most likely in favor of assisting the police in reducing supporter violence, a reason may be that the home-field advantage may disappear, since some unruly supporters may in fact help their team to win. The policy implication is that law-enforcement officers can use this information when deciding on police deployment and which type of payment mechanisms to use; see also Nyberg and Priks (2013).

The paper proceeds as follows. Section 2 deals with the data and empirical strategy. Section 3 shows the results and Section 4 concludes.

\section{Data and empirical strategy}

The referees in the highest Swedish soccer league, Allsvenskan, file a report after every game. I used data from these reports, which include information on goals, yellow and red cards, the number of spectators and the identity of the referees. Data on the number of organized supporters for both home and away teams was obtained from the Swedish National Police Force. It is based on intelligence work by the police, who monitor the supporters, and the number of tickets sold to members of supporter clubs. Many of these supporters stand together behind one of the goals. They typically wear clothes with their team's colors, chant songs and slogans to support the players of their own team and some even throw objects to put pressure on the other players and the referees. Weather data from the different locations where soccer in Allsvenskan is played are collected by the Swedish Meteorological and Hydrological Institute.

Table 1 reports the summary statistics from the seasons 1999-2005, and shows that Swedish soccer is characterized by a strong home-field advantage. The home team won in 44 percent of the games. In 30 percent of the games there was a draw and in 26 percent of the games the away team won. The home team scored, on average, 1.54 goals per game and the away teams scored 1.20 goals. The number of spectators varied 
between 503 and 42,386. On average, 8,733 spectators attended one of the 1,273 games. ${ }^{4}$ The police reported the number of organized home supporters in 838 games. On average, 900 organized home supporters attended a game. The average amount of precipitation during a pre-game day (measured at 6 p.m. during the previous 12-hour period) is 2,07 ml. The correlation coefficient between precipitation in the pre-game day and the game day is 0.23 .

TABLE 1. SUMMARY STATISTICS

\begin{tabular}{lccccc}
\hline \hline & Mean & St.Dev. & Min & Max & Obs. \\
\hline Home win & 0.44 & 0.5 & 0 & 1 & 1,273 \\
Away win & 0.3 & 0.46 & 0 & 1 & 1,273 \\
Draw & 0.26 & 0.44 & 0 & 1 & 1,273 \\
Home goals & 1.54 & 1.33 & 0 & 8 & 1,273 \\
Away goals & 1.20 & 1.14 & 0 & 8 & 1,273 \\
Organized home supporters & 900 & 1,228 & 0 & 11,500 & 838 \\
All spectators & 8,733 & 5,989 & 503 & 42,386 & 1,273 \\
Precipitation pre-game day & 2.07 & 4.85 & 0 & 43.2 & 1,260 \\
Precipitation game day & 2.18 & 5.00 & 0 & 50.6 & 1,260 \\
\hline
\end{tabular}

I used 2SLS specifications to isolate the mechanism. The exogeneity of the variation in precipitation is crucial for the identification strategy. In the first-stage regression, precipitation during a pre-game day is used to instrument for the number of organized home supporters. I ran

$$
X_{c t}=a_{c}+b Z_{c t}+\theta S_{t}+\varepsilon_{c t}
$$

where $X_{c t}$ denotes the number of organized home supporters in match combination $c$ in period $t$ (spring or fall season). The term $a_{c}$ denotes match-combination fixed effects, $Z_{c t}$ precipitation, $S_{t}$ season fixed effects for every spring and fall and $\varepsilon_{c t}$ is a disturbance term. The second-stage equation estimates the impact of the number of organized home supporters on the probability of a home win $Y_{c t}$ :

$$
Y_{c t}=\alpha_{c}+\beta X_{c t}+\lambda S_{t}+\mu_{c t}
$$

\footnotetext{
${ }^{4}$ One game was played with empty grandstands due to a previous hooligan incident. This observation is therefore excluded. The results do not change qualitatively when the observation is included.
} 


\section{Results}

Table 2 shows the reduced-form regression. Higher levels of precipitation (which in almost all cases was in the form of rain) are associated with significantly fewer home wins. If it rains during a pre-game day, then it rains, on average, $5 \mathrm{ml}$. The probability of a home win is reduced by 4 percent. This is the first indication that precipitation affects the home-field advantage. The first-stage relationship between precipitation and the number of organized home supporters is very strong.

TABLE 2. PRECIPITATION AND THE HOME-FIELD ADVANTAGE (Reduced form) Dependent variable: Home win

\begin{tabular}{lc}
\hline Sample & {$[1]$} \\
\hline Precipitation Pre-game day & $-0.0073^{*}$ \\
Constant & $(0.0036)$ \\
& $0.491 * * *$ \\
$\mathrm{R}^{2}$ & $(0.084)$ \\
Observations & 0.35 \\
\hline
\end{tabular}

Note: $* * *$ indicates signficance at the 1 percent level, $* *$ at the 5 percent level, and $*$ at the 10 percent level. The regressions include game-fixed effects and season-fixed effects. The standard errors are clustered at the level of the home teams.

Table 3 (column 1, panel B) shows that $5 \mathrm{ml}$. precipitation leads to approximately 80 fewer organized home supporters, which corresponds to almost a 10 percent reduction. The result is significant at the 1 percent level. Panel A reports the result from the second stage. Column 1 shows that an increase in the number of organized home supporters by 80 (following a $5 \mathrm{ml}$. change in precipitation) tends to increase the probability of a home win by 4 percent. This result is significant at the 5 percent level.

Precipitation is clearly an exogenous instrument, but it should also satisfy the exclusion restriction: weather shocks should affect the game outcome solely through the number of organized supporters. It can be argued that a wet field leads to more randomness in the outcome of games. To control for this possibility, I ran the main 2SLS regression using precipitation during game day as a control. The results reported in column 2 of Table 3 are virtually the same as before. ${ }^{5}$

\footnotetext{
${ }^{5}$ The results are also robust to the inclusion of referee-fixed effects.
} 
TABLE 3. SOCIAL PRESSURE AND THE HOME-FIELD ADVANTAGE

\begin{tabular}{|c|c|c|c|c|}
\hline & [1] & [2] & [3] & [4] \\
\hline Panel A (Second stage) & \multicolumn{4}{|c|}{ Dependent variable: Home win } \\
\hline Org. home supporters & $\begin{array}{c}0.054^{* *} \\
(0.022)\end{array}$ & $\begin{array}{c}0.050^{* *} \\
(0.022)\end{array}$ & & \\
\hline All spectators & & & $\begin{array}{c}0.015 \\
(0.014)\end{array}$ & $\begin{array}{c}0.013 \\
(0.014)\end{array}$ \\
\hline Precipitation game day & & $\begin{array}{l}-0.004 \\
(0.005)\end{array}$ & & $\begin{array}{l}-0.004 \\
(0.005)\end{array}$ \\
\hline Constant & $\begin{array}{c}-3.26^{* *} \\
(1.71)\end{array}$ & $\begin{array}{c}-2.95^{* * *} \\
(1.31)\end{array}$ & $\begin{array}{l}-3.99 \\
(3.97)\end{array}$ & $\begin{array}{l}-3.38 \\
(3.93)\end{array}$ \\
\hline Observations & 825 & 825 & 1,258 & 1,258 \\
\hline Panel B (First stage) & $\begin{array}{l}\text { Dependen } \\
\text { column }[1\end{array}$ & $\begin{array}{l}\text { ables: Orga } \\
\text { [2] and all s }\end{array}$ & $\begin{array}{l}\text { home sup } \\
\text { ators in coll }\end{array}$ & $\begin{array}{l}\text { s in } \\
\text { 3] and [4]. }\end{array}$ \\
\hline Precipitation Pre-game day & $\begin{array}{c}-0.167 * * * \\
(0.061)\end{array}$ & $\begin{array}{c}-0.166^{* * *} \\
(0.061)\end{array}$ & $\begin{array}{c}-0.479 * * \\
(0.224)\end{array}$ & $\begin{array}{c}-0.487^{* *} \\
(0.231)\end{array}$ \\
\hline Preciptiation Game day & & $\begin{array}{l}-0.007 \\
(0.055)\end{array}$ & & $\begin{array}{c}0.032 \\
(0.217)\end{array}$ \\
\hline Constant & $\begin{array}{c}58.06^{* * *} \\
(6.84)\end{array}$ & $\begin{array}{c}58.09^{* *} \\
(6.85)\end{array}$ & $\begin{array}{c}186.82 * * * \\
(15.20)\end{array}$ & $\begin{array}{c}286.83 * * * \\
(15.21)\end{array}$ \\
\hline Observations & 825 & 825 & 1,258 & 1,258 \\
\hline
\end{tabular}

Note: $* * *$ indicates signficance at the 1 percent level, ${ }^{* *}$ at the 5 percent level, and $*$ at the 10 percent level. The attendence is multiplied by 100 . The regressions include game-specific fixed effects and season-fixed effects. The standard errors are clustered at the level of the home teams.

The previous literature has only had access to the number of spectators at large, which includes organized supporters, families, business people, etc. It is interesting to study whether this variable affects the outcome of games when the endogeneity problem is addressed. To this end, two instruments would be required. However, with only one instrument, an alternative - and more suggestive - approach to separating the two effects is to redefine the endogenous variable to include not only organized home supporters but all spectators in the stadium. Column 3 in Table 3 shows that $5 \mathrm{ml}$. of rain leads to 240 fewer spectators in the stadium (Panel B). However, in contrast to the organized home supporters who manage to influence games through social pressure, and in contrast to the findings in earlier studies, the result in column 3 in Panel A shows that spectators at large 
do not affect the game. The result is not altered when precipitation during pre-game day is controlled for in column 4.

In Table 4, I report the results when the dependent variable is home goals (column 1) and then away goals (column 2). An increase by 80 organized following again following a home supporters leads to 0.06 more home goals per game. This amounts to a 4-percent increase in the number of goals and the result is significant at the 5-percent level. However, the number of organized home supporters does not significantly affect the number of away goals. The results show that compared to a game without organized home supporters, the average-size home crowd, 900 supporters, manages to generate 0.6 home goals.

\section{TABLE 4. SOCIAL PRESSURE, HOME AND AWAY GOALS, AND CARDS}

\begin{tabular}{|c|c|c|c|c|}
\hline & {$[1]$} & [2] & [3] & [4] \\
\hline Panel A (Second stage) & \multicolumn{4}{|c|}{$\begin{array}{l}\text { Dependent variables: Home goal in column [1], away goals } \\
\text { in column [2], yellow home cards - yellow away cards in } \\
\text { column [3] and red home cards - red away cards in column [4]. }\end{array}$} \\
\hline Organized home supporters & $\begin{array}{c}0.081 * * \\
(0.040)\end{array}$ & $\begin{array}{l}-0.041 \\
(0.070)\end{array}$ & $\begin{array}{c}0.032 \\
(0.140)\end{array}$ & $\begin{array}{l}-0.020 \\
(0.031)\end{array}$ \\
\hline Precipitation game day & $\begin{array}{l}-0.005 \\
(0.013)\end{array}$ & $\begin{array}{c}0.007 \\
(0.008)\end{array}$ & $\begin{array}{l}-0.014 \\
(0.024)\end{array}$ & $\begin{array}{l}-0.001 \\
(0.003)\end{array}$ \\
\hline Constant & $\begin{array}{l}-3.35 \\
(2.29)\end{array}$ & $\begin{array}{c}3.70 \\
(3.95)\end{array}$ & $\begin{array}{c}1.68 \\
(8.58)\end{array}$ & $\begin{array}{c}1.65 \\
(1.83)\end{array}$ \\
\hline Observations & 825 & 825 & 825 & 825 \\
\hline
\end{tabular}

Panel B (First stage)

Precipitation pre-game day

Preciptiation game day

Constant

Observations
Dependent variable: Organized home supporters

$\begin{array}{cccc}-0.166 * * * & -0.166^{* * *} & -0.162^{* * *} & -0.162^{* * *} \\ (0.061) & (0.061) & (0.063) & (0.063) \\ -0.007 & -0.007 & -0.018 & -0.018 \\ (0.055) & (0.055) & (0.057) & (0.057) \\ 58.09 * * & 58.09 * * & 60.24 * * & 60.24 * * \\ (6.85) & (6.85) & (9.20) & (9.20) \\ 825 & 825 & 825 & 825\end{array}$

825
825 level. The variable organized home supporters is multiplied by 100 . The regressions include game-specific fixed effects and season-fixed effects. The regressions in column [3] and [4] include referee-fixed effects. The standard errors are clustered at the level of the home teams. 
Finally, the analysis does not reveal whether it is the players or the referees who are affected by social pressure. I addressed this by studying if home supporters affect the number of yellow and red cards handed out by referees. Referees control the games by having the possibility to adjudicate fouls, yellow cards, and red cards. If a player receives two yellow cards, or one instant red card, then he is sent off the pitch. As shown in Table 4, columns 3 and 4, I do not find that referees treat home teams better in terms of yellow and red cards when there are more organized home supporters in the stadium. This indicates that it is the players rather than the referees who are affected by social pressure. An alternative explanation is that the pressure is directed more towards the players than the referees.

\section{Conclusions}

This paper contributes to an emerging empirical literature which attempts to identify the effects of social pressure on individuals' behavior. I address this question by studying the home-field advantage in sports. In order to separate the endogeneity between the outcome of games and the size of the crowd, I use precipitation as an instrument for the number of organized home supporters. I find that these supporters manage to influence the game outcome such that there are more home goals, which leads to significantly more home wins. Suggestive evidence indicates that the players rather than the referees are affected by social pressure. In contrast to the previous literature, I do not find that the number of spectators as a whole affects the players or the referees.

Pressure inside the arenas is intense, but the players are highly skilled, highly paid and used to their working environment since games are played week after week. This evidence suggests that individuals in other professions may also be affected by social pressure from spectators, or possibly the media or peers.

The results also reveal why soccer clubs tend to be reluctant to participate in combating hooliganism. Organized supporters, some of whom are violent, help the teams to win. This places the clubs in a prisoner's dilemma-like situation where each club wants to create a home-field advantage. However, if they all behave in the same way, they will all lose by having overly aggressive supporters. This insight can help policy makers in setting up mechanisms to deter hooliganism. 


\section{References}

[1] Akerlof, George A. and Kranton, Rachel E. (2000), “Economics and Identity,” Quarterly Journal of Economics, 115: 715-753.

[2] Balmer, Nigel J.; Nevill, Allan M. and Lane, Andrew M. (2005), “Do Judges Enhance Home Advantage in European Championship Boxing?”, Journal of Sports Sciences, 23: 409-416.

[3] BBC (2003), “Fans may Meet Cost of Hooligans”, April 9.

[4] Clarke, Stephen R. and Norman, John M. (1995), "Home Ground Advantage of Individual Clubs in English Soccer”, The Statistician, 44: 509-521.

[5] Della Vigna, Stefano, List, John A. and Malmendier, Ulrike (2012), “Testing for Altruism and Social Pressure in Charitable Giving”, Quarterly Journal of Economics, 127: $1-56$.

[6] Dohmen, Thomas (2008a), “The Influence of Social Forces: Evidence from the Behavior of Football Referees”, Economic Inquiry, 46: 411-424.

[7] Dohmen, Thomas (2008b), “Do Professionals Choke under Pressure?”, Journal of Economic Behavior \& Organization, 65: 636-653.

[8] Falk, Armin and Ichino, Andrea (2006), “Clean Evidence on Peer Effects”, Journal of Labor Economics, 24: 39-57.

[9] Garicano, Luis, Palacios-Huerta, Ignacio and Prendergast, Canice (2005), "Favoritism under Social Pressure”, Review of Economics and Statistics, 87, 208-216.

[10] Gerber, Alan S.; Green, Donald P. and Larimer, Christopher W. (2008), “Social Pressure and Voter Turnout: Evidence from a Large-Scale Field Experiment”, American Political Science Review, 102: 33-48.

[11] Guardian (2009), "Police Want Football Clubs to Pay More for their Match-Day Service”, August 28.

[12] Koning, Ruud H. (2005), "Home Advantage in Speed Skating: Evidence from Individual Data”, Journal of Sports Sciences, 23: 417-427.

[13] Mas, Alexandra and Moretti, Enrico (2009), "Peers at Work”, American Economic Review, 99: 112-145.

[14] Miguel, Edward (2005), “Poverty and Witch Killing”, Review of Economic Studies, 72: 1153-1172. 
[15] Miguel, Edward, Satyanath, Shanker and Sergenti, Ernest (2004), "Economic Shocks and Civil Conflict: An Instrumental Variables Approach”, Journal of Political Economy, 112: 725-753.

[16] Morley, Bruce and Dennis, Thomas (2005), “An Investigation of Home Advantage and Other Factors Affecting Outcomes in English One-day Cricket Matches”, Journal of Sports Sciences, 23: 261-268.

[17] Neave, Nick and Wolfson, Sandy (2003), “Testosterone, Territoriality and the Home Advantage”, Physiology and Behavior, 78: 269-275.

[18] Nevill, Alan M. and Holder, Roger L. (1999), "Home Advantage in Sport: An Overview of Studies on the Advantage of Playing at Home”, Sports Medicine, 28: 221236.

[19] Nyberg, Sten and Priks, Mikael (2013),“Public Order, Private Payments? Sharing the Costs of Police at Events”, Mimeo, Stockholm University.

[20] Paxson, Christina H. (1992), “Using Weather Variability to Estimate the Response of Savings to Transitory Income in Thailand”, American Economic Review, 82 : 15-33.

[21] Pettersson-Lidbom, Per and Priks, Mikael (2010), “Behavior under Social Pressure: Empty Italian Stadiums and Referee Bias”, Economics Letters, 108: 212-214.

[22] Pollard, Richard (2002), "Evidence of a Reduced Home Advantage when a Team Moves to a New Stadium”, Journal of Sports Sciences, 20: 969-973.

[23] Schwartz, Barry and Barsky, Stephen F. (1977), “The Home Advantage”, Social Forces, 55: 641-661.

[24] Sutter, Matthias and Kocher, Martin G. (2004), "Favoritism of Agents - the Case of Referees’ Home Bias”, Journal of Economic Psychology, 25: 461-469. 